\title{
ANÁLISE DA PRODUÇÃO CIENTÍFICA DA ARQUIVOLOGIA NO BRASIL: UMA REVISÃO DE LITERATURA
}

\author{
ANALISIS DE LA PRODUCIÓN CIENTÍFICA DE \\ ARCHIVOLOGÍA EN BRASIL: UNA REVISIÓN DE LA \\ LITERATURA
}

José Mauro Gouveia de Medeiros* Jayme Leiro Vilan Filho**

\begin{abstract}
RESUMO
Introdução: revisão de literatura resultante de levantamento bibliográfico sobre a literatura científica da Arquivologia brasileira.

Objetivo: identificar aspectos da literatura científica da Arquivologia, através da pesquisa bibliográfica que busca apresentar características da configuração da Arquivologia no Brasil.

Metodologia: utilizou como fontes as bases de dados, portais e serviços de referência brasileiros para identificar 523 referências das quais 15 textos foram selecionados e analisados em relação a autoria, afiliação, ano, tipo de publicação, tipo e tamanho das fontes usadas, método, abrangência geográfica, resultados, entre outros aspectos.

Resultados: os artigos científicos foram o principal objeto de estudo; o livro foi o canal mais citado; o periódico Arquivo \& Administração e o Encontro Nacional de Pesquisa em Ciência da Informação têm a importância no cenário nacional; o Rio de Janeiro é a região geográfica com maior produção; houve crescimento do número de trabalhos a partir do ano 2007 e aumento da colaboração.

Conclusões: o interesse pela literatura de Arquivologia está aumentando de forma significativa; houve diversificação dos canais de publicação, principalmente trabalhos de eventos e artigos a partir de 2013; a Arquivologia está se consolidando no Brasil com o aumento de produção, colaboração e interesse pela sua literatura científica.
\end{abstract}

Palavras-chave: Revisão de literatura. Comunicação científica. Arquivística. Brasil. Bibliometria.

*Mestrando do Programa de Pós Graduação em Ciência da Informação (PPGCINF) da Faculdade de Ciência da Informação (FCl) da Universidade de Brasília (UnB). E-mail: maurogouveiamedeiros@yahoo.com.br

*Professor do Programa de Pós Graduação em Ciência da Informação (PPGCINF) da Faculdade de Ciência da Informação (FCI) da Universidade de Brasília (UnB). E-mail: jleiro@unb.br 


\section{INTRODUÇÃO}

A consolidação de uma área do saber, no campo científico, necessita, concomitantemente, de três indícios de sua maturidade e institucionalização: a literatura científica, as associações ou sociedades de pesquisas e os cursos regulares de formação profissional e de pesquisadores (MUELLER; CAMPELLO; DIAS, 1996, p. 1).

Uma das formas de transmissão dos resultados de pesquisas é a publicação de artigos em periódicos científicos, de livros e capítulos de livros. $\mathrm{O}$ artigo científico é para o cientista um "meio de comunicar o conhecimento" (PRICE, 1976) de forma sistemática nos fascículos de revistas ou periódicos científicos. O periódico é, de fato, um dos meios de comunicação mais utilizados para transmissão de resultados de pesquisas. Esta predileção pode ser atribuída à "facilidade de publicação, levando a um crescimento expressivo dessa forma de difusão científica" (CÔRTES, 2006, p. 48). Há de se considerar, também, a credibilidade desse canal junto à comunidade científica que, por sua vez, avalia, junto aos seus pares, a pertinência e qualidade dos trabalhos publicados.

A difusão de pesquisas ocorre também em eventos científicos, que podem ser definidos como "um acontecimento que implica a apresentação e, ou, exibição pública, para a população em geral ou para clientela específica, do conhecimento ou produto cultural, artístico, esportivo, científico ou tecnológico produzido" (CORREAA; VASCONCELOS; SOUZA, 2009, p. 12) ou também como "meios mais informais e, com efeito, mais ágeis na transmissão e troca do conhecimento científico" e que "congregam pessoas com interesse comum, estimulam a troca e compartilhamento de conhecimento e a criação de novas parcerias ou grupos" (ARBOIT \& BUFREM, 2013, p. 89). O comportamento e as escolhas dos canais de comunicação variam de acordo com as especificidades de cada campo do saber, conforme nos aponta o estudo de Mueller (2005). Essa perspectiva é também defendida por Meadows (1999, p. 1), ao argumentar que a transmissão de informações do cientista depende do "veículo empregado, da natureza das informações e do público-alvo". 
A temática da Arquivologia está presente em eventos próprios da área e no de áreas afins, de caráter interdisciplinar. O principal deles, o Encontro Nacional de Pesquisa em Ciência da Informação (ENANCIB), é promovido pela Associação Nacional de Pesquisa e Pós-Graduação em Ciência da Informação (ANCIB). É realizado desde 1994, tendo sido realizadas 16 edições até o ano de 2015.

Após os levantamentos realizados em diversas bases de dados e fontes, constatou-se que são poucos os trabalhos que investigam as características da produção científica da Arquivologia no Brasil. Assim, o problema desta pesquisa situa-se na inexistência de um panorama atual desta literatura referente aos artigos de periódicos científicos e dos trabalhos apresentados no ENANCIB.

O objetivo desta pesquisa é realizar uma revisão de literatura sobre a produção científica da Arquivologia no Brasil, contemplando os artigos de periódicos científicos e os trabalhos apresentados no ENANCIB entre 1994 e 2014 e, de forma complementar, a leitura e análise de uma monografia e uma dissertação. Ademais, pretende-se identificar as características, bem como as metodologias adotadas e os resultados alcançados. Entende-se que a publicação de artigos científicos em periódicos e as apresentações nas reuniões do ENANCIB são maneiras de transmitir o conhecimento produzido que pode refletir sua consolidação.

\section{PROCEDIMENTOS METODOLÓGICOS}

Foi realizada, no início de 2015, consulta na base de dados especializada no Programa de Pós-Graduação em Ciência da Informação da Universidade de Brasília, a ABCDM, recuperando-se 151 registros, dos quais cinco mantinham relação com o objeto estudado. Ao Setor de Referência da Biblioteca Central da Universidade de Brasília solicitou-se uma pesquisa que abordasse a produção científica arquivística que apresentou o seguinte número de registros: 33 no portal de eventos da Associação Nacional de Pesquisa e Pós-Graduação em Ciência da Informação (ANCIB); 153 na Base de Dados 
Referencial de Artigos de Periódicos em Ciência da Informação (BRAPCI); 62 na Biblioteca de Teses e Dissertações do Instituto Brasileiro de Informação, Ciência e Tecnologia (BICT); 118 no Repositório Institucional da Universidade de Brasília. Deste total de 366 registros, apenas quatro relacionava-se ao tema. Complementando a pesquisa, consultou-se o portal de periódicos da Coordenação de Aperfeiçoamento de Pessoal de Nível Superior (Capes), recuperando-se quatro textos de interesse. Dois registros foram encontrados em pesquisa na internet, por meio do site Google Acadêmico. Após levantamento dos dados, selecionou-se os que atendiam ao objetivo deste artigo. Do total de 523 registros obtidos nas fontes descritas acima, somente 15 $(2,87 \%)$ contemplaram reflexões sobre a produção científica arquivística brasileira, identificados na leitura de resumos e palavras-chave. Em seguida, no decorrer do primeiro semestre de 2015, procedeu-se à leitura e análise dos trabalhos selecionados que serão apresentadas a seguir.

\section{DÉCADA DE 1990}

A primeira pesquisa acerca da produção do conhecimento arquivístico foi realizada por Jardim (1998). Ele analisou a publicação de artigos no Brasil entre os anos de 1990 e 1995. Sua análise partiu da constatação de que "entre os indicadores mais utilizados na medida da produção científica está o número e diversidade de publicações de um país, região, universidade, unidade acadêmica, grupo de pesquisa ou cientista individual", considerando-se também que "o conhecimento publicado constitui um dos elementos de análise de produtividade científica". À época, segundo o autor, não havia nenhum periódico específico da área ${ }^{1}$, o que por ele foi considerado um "grave problema de comunicação científica no campo arquivístico no país". Seu levantamento de dados foi realizado em cinco bibliotecas, resultando em 14 periódicos das áreas de Ciência da Informação $(\mathrm{Cl})$, Biblioteconomia, Administração e História, que, conjuntamente, possuíam 51 artigos, dez relatos de experiência e seis comunicações. Os resultados demonstraram, entre outras

\footnotetext{
1 Ao contrário do que aconteceu com outros autores, Jardim não considerou o periódico Arquivo \& Administração como periódico específico arquivístico.
} 
constatações, que: a) há um baixo índice na média anual de publicação de artigos, comunicações e relatos de experiências de autores nacionais $(7,8)$, indicando pequena produtividade; b) o Rio de Janeiro concentrava os maiores números de periódicos científicos (40\%), artigos (61\%) e autores (67\%); c) $51 \%$ dos títulos publicados eram oriundos de organizações arquivísticas e $47 \%$ de universidades; d) concentração de um seleto grupo de autores $(35 \%) \mathrm{com}$ maior índice de produtividade (considerando-se a produção de mais de um artigo, relato de experiência ou comunicação); e) identificação das temáticas mais estudadas: tecnologias aplicadas aos arquivos e à legislação (25\%), políticas arquivísticas, classificação, formação profissional, arranjo e descrição (13\%), e teoria arquivística (11\%). De acordo com os dados pesquisados, não foi identificado outro trabalho publicado anteriormente sobre a produção científica arquivística no Brasil, o que Ihe confere importância atribuída ao ineditismo do estudo à época em que foi publicado. A partir da leitura do trabalho de Jardim (1998), pode-se constatar que o índice de produtividade da área foi considerado pequeno para a produção científica no período analisado. Para o autor, a condição de disciplina científica atribuída à Arquivologia somente será alcançada se "forem realizados investimentos na pesquisa como estratégia de produção do conhecimento". Nesse contexto, a inexistência de periódicos específicos arquivísticos influenciou a decisão de publicar-se artigos científicos arquivísticos em periódicos de outras áreas do saber. Ressalta-se a importância das instituições arquivísticas e das universidades que foram grandes produtores de conhecimento científico.

\section{DÉCADA DE 2000}

Após quase uma década de publicação do primeiro trabalho analisado, a literatura arquivística brasileira foi pesquisada por Costa (2007) que produziu um artigo decorrente de trabalho monográfico apresentado no ano anterior. Foi realizado um mapeamento da produção bibliográfica no Brasil no período entre 1960 e 2006. O objetivo foi identificar aspectos da produção, tradução e edição de livros. O levantamento dos dados foi realizado em quatro bibliotecas 
públicas (Biblioteca do Arquivo Nacional, Biblioteca do Arquivo Público do Estado do Rio de Janeiro, Biblioteca da Universidade Federal do Rio de Janeiro e Biblioteca do Centro Cultural do Banco do Brasil) e em pesquisas na internet. As condições para considerar as obras como objetos de estudos eram possuir mais de 49 páginas e ser produzida, editada e/ou traduzida no Brasil entre 1960-2006. Além disso, os títulos deveriam conter os termos "arquivo", "arquivologia", "arquivística", e respectivas derivações. Com base nessas especificações, foram encontradas 77 obras, das quais 57 (74\%) eram de autores brasileiros, $9(11,6 \%)$ de organizadores de livros e 12 (15,6\%) livros internacionais, traduzidos e publicados no Brasil. As maiores autorias brasileiras são de Heloísa Bellotto, Ana Maria Camargo, José Maria Jardim e Luís Carlos Lopes, cada qual com quatro publicações. O autor distinguiu as obras pesquisadas entre manuais e não manuais. Para serem considerados como manuais, os livros deveriam: tratar do fazer arquivístico; conter verbos no infinitivo, tais como, "fazer", "organizar", "avaliar", "implantar", "descrever", "tratar", "elaborar", entre outros; e, por fim, haver em seus títulos termos como "manual", "recomendação", "organização", "roteiro", "técnicas" ou termos que remetessem à noção do "fazer". Considerando essa classificação, 51 dos livros foram classificados como manuais $(66,2 \%)$ e 26 como não manuais $(33,8 \%)$. Para o autor, houve crescimento considerável na produção bibliográfica arquivística publicada no Brasil. Outra constatação feita por ele é que o aumento da produção bibliográfica colabora para o reconhecimento da Arquivologia como campo autônomo e disciplina científica. Esse trabalho evidencia que, embora já estabelecida como área do saber que possui considerável produção científica, necessita de maior engajamento por parte dos profissionais arquivistas na construção do conhecimento.

Dois anos depois foi publicado por Pinto, Santos e Santos (2009) um trabalho em que o periódico científico eletrônico Arquivística.net foi objeto de estudo bibliométrico a partir da análise de citação em artigos científicos publicados no período de 2005 a 2007. Os termos "arquivologia" e "arquivística" foram utilizados como sinônimos. O trabalho identificou 27 artigos que continham 461 referências bibliográficas. A pesquisa revelou que: houve predominância de autoria individual $(55,51 \%)$ em relação à coautoria $(44,91 \%)$; 
no tocante às citações, $68 \%$ eram de autorias únicas, $21 \%$ de autorias múltiplas e $11 \%$ de autorias de entidades; as fontes de informação mais utilizadas são os livros (36\%), sendo que também foram identificados artigos de periódicos $(34 \%)$, normas técnicas $(7 \%)$ e outras $(23 \%)$; o português foi o idioma com maior destaque (68\%), seguido do inglês (21\%), espanhol $(9 \%)$ e francês (2\%). Também, identificou-se que a vida média da literatura utilizada (citada e referenciada) varia entre quatro e cinco anos. Ao identificar a localidade de publicação dos documentos citados, os autores fizeram distinção entre as origens nacional e estrangeira, e, em seguida, pelas regiões brasileiras, cujos dados foram: $83 \%$ são citações de autores brasileiros e 17\% de estrangeiros; em relação às regiões brasileiras, os dados revelam que $47 \%$ são do Sudeste, $10 \%$ do Centro-Oeste, $3 \%$ do Sul, $2 \%$ do Nordeste e $38 \%$ não possuem tal informação; a respeito das cidades brasileiras, o Rio de Janeiro desponta com 30\%, seguida de São Paulo (10\%), Brasília (7\%) e Niterói (3\%), as demais cidades oscilavam com percentual entre 2 e $1 \%$; os países que apresentaram os percentuais mais expressivos foram Portugal e Espanha (20\% cada), Canadá (14\%) e França (10\%). Os autores brasileiros mais citados são Luís Carlos Lopes e José Maria Jardim, com respectivamente oito e seis citações; os autores internacionais mais citados foram Armando B. Malheiro da Silva (oito citações) e Jean-Yve Rosseau e Carol Couture (sete citações). Alguns dados desse estudo são confirmados por outros trabalhos aqui analisados. De modo geral, o trabalho reflete a preocupação de se estudar aspectos da literatura científica arquivística no Brasil, que estava se institucionalizando no país.

\section{DÉCADA DE 2010}

A relação entre o conhecimento arquivístico e a Ciência da Informação (Cl) foi investigada por Medeiros, Nodare e Araújo (2010), por meio de análises bibliométricas aplicadas ao periódico Arquivo \& Administração. Os autores coletaram 21 trabalhos, entre 2004 e 2006, analisando os dados selecionados sob a perspectiva de sua incidência nas seis correntes teóricas da Ciência da Informação: estudos quantitativos da informação, estudos vinculados à teoria 
sistêmica, teoria crítica, estudos em representação e classificação, estudos sobre as redes e fluxos da informação e, por fim, estudos de usuários. Os pontos selecionados para análise foram: autoria, vinculação dos autores, vinculação dos trabalhos às correntes teóricas da $\mathrm{Cl}$, caracterização das referências quanto aos autores citados, ano e tipologia. Pesquisaram-se nos títulos, palavras-chave ou introdução os termos "arquivologia", "arquivística (o)", "archivística", "arquivo", "archivo" ou "arquivista". Obteve-se o seguinte resultado em relação às correntes teóricas da $\mathrm{Cl}$ : teoria sistêmica (9), estudos em representação e classificação (4), estudos de usuários (4), estudos sobre as redes e fluxos da informação (3) e teoria crítica (1). Das 24 autorias dos trabalhos, apenas três autores produziram dois trabalhos - Armando Malheiro, José Maria Jardim e Ingrid Beck -, os demais escreveram apenas um. A categorização geográfica dos autores foi realizada a partir da identificação de suas vinculações institucionais. A procedência nacional contou com 15 incidências; já a internacional, oito incidências. As referências foram apresentadas cronologicamente pelo número de trabalhos e pela quantidade de referências da seguinte forma: 2004 (quatro trabalhos e 113 referências), 2005 (nove trabalhos e 119 referências), 2006 (oito trabalhos e 162 referências). Elas foram analisadas também da seguinte maneira: número de referências por autor (com média de 18,76); autocitações (média de 3,4 por autor e 1,92 por artigo); idiomas (191 referências nacionais e 203 internacionais, sendo que os idiomas identificados eram espanhol, francês, inglês e outros); ano (separados pelos seguintes períodos cronológicos: 18901919 (1), 1920-1929 (1), 1930-1939 (2), 1940-1949 (2), 1950-1959 (4), 19601969 (3), 1970-1979 (15), 1980-1989 (27), 1990-1999 (148), 2000-2006 (178) e mais 13 referências sem data; e autores mais citados, considerando-se o número mínimo de três citações, foram excluídos alguns autores, restando 27 autores, nos quais destacaram-se José Maria Jardim (19 citações), Armando Malheiro da Silva (15 citações), Fernanda Ribeiro (13 citações), Carol Culture (13 citações) e Maria Odila Fonseca (12 citações). Este trabalho reflete a interrelação entre a Arquivologia e a Ciência da Informação, constatada a partir da incidência dos temas arquivísticos relacionados às correntes teóricas da $\mathrm{Cl}$. Um fato chama atenção: a concentração relativa dos trabalhos (25\%) por parte 
de um grupo de pesquisadores, ao tempo em que a maioria dos autores produz apenas um trabalho. Destaca-se, ainda, em termos de vinculação institucional geográfica dos 24 autores dos 21 trabalhos analisados, o desenvolvimento da pesquisa nacional (15) em relação à internacional (8), sendo que em um dos trabalhos não foi possível identificar tal variável.

Outro estudo bibliométrico relacionado a um tema de interesse arquivístico foi identificado no ano seguinte. Trata-se do trabalho de Bahia, Santos e Blattmann (2011), no qual foi realizada uma análise bibliométrica acerca da preservação digital, a partir de dados coletados na base Library and Information Science Abstracts (LISA). Segundo esses autores, o tema vinha se destacando pela visibilidade e importância no mundo moderno e, no campo arquivístico, pelas mudanças dos paradigmas de arquivos. O corpus da pesquisa foram as referências bibliográficas de 1.750 artigos científicos contidos em 153 títulos de periódicos indexados na base LISA no período entre 1975 e 2009. Foi apresentada uma lista com os nomes dos 20 principais periódicos na área de preservação digital. Enquanto 60 títulos de periódicos cobrem $85,9 \%$ dos artigos sobre o tema, outros 93 títulos respondem pela cobertura de apenas $14,1 \%$. Os autores apontaram também que os estudos bibliométricos contribuíram para investigar o registro da literatura técnicocientífica. Trata-se de uma pesquisa que reconheceu a importância da bibliometria como ferramenta capaz de auferir vários aspectos da produção científica. Os dados revelaram que o tema da preservação digital vinha sendo indexado pela base LISA, o que possibilitava aos interessados no assunto recuperarem trabalhos para efetuarem suas pesquisas.

Em outra pesquisa publicada no mesmo ano foram analisados por meio de um estudo bibliométrico os artigos e respectivas autorias de periódicos científicos brasileiros de Arquivologia publicados entre 1972 e 2007 (VILAN FILHO; OLIVEIRA, 2011). Apesar de terem sido recuperados 400 registros de quatro periódicos científicos, somente dois periódicos foram analisados Arquivo \& Administração e Arquivística.net. Os critérios adotados para identificação de periódicos especificamente arquivísticos basearam-se na política editorial dos títulos e na temática dos artigos, que deveriam alcançar o percentual mínimo de $50 \%$ de artigos sobre a área arquivística. Desta forma, 
restaram 143 artigos dos dois únicos periódicos brasileiros considerados especificamente arquivísticos. A pesquisa identificou gradual queda na produção de artigos sobre Arquivologia nas décadas de 1980 e 1990, respectivamente 30 e 20 artigos, cujos índices cresceram nos anos 2000 (48 artigos), aproximando-se do valor da década de 1970 (45 artigos). Acerca das autorias dos periódicos, identificou-se que a maior parte procedeu de instituições localizadas no Rio de Janeiro $(65,74 \%)$, enquanto as autorias estrangeiras ocupam o segundo lugar $(22,22 \%)$, sendo o terceiro e quarto lugares ocupados, respectivamente, por Distrito Federal (13,89\%) e São Paulo $(11,11 \%)$. Ao analisarem a colaboração entre pesquisadores nos periódicos específicos arquivísticos, os autores identificaram o crescimento de artigos produzidos em autoria múltipla, com os seguintes índices: 22,84\% (1972-2007), $28,75 \%$ (1991-2007) e 32,20\% (2001-2007). A interdisciplinaridade da Arquivologia com periódicos de diferentes áreas contribuiu para a disseminação de produção científica no período analisado, suprindo a necessidade causada pela escassez de periódicos científicos específicos correntes. Alguns destaques dessa pesquisa são: crescimento da produção de artigos; ampliação dos canais para publicação de resultados de pesquisas com temáticas arquivísticas; maior extensão geográfica de autoria, embora ainda haja concentração no Rio de Janeiro, com índices variando em cada periódico ( $75 \%$ na Arquivo \& Administração e $25 \%$ no Arquivística.net); crescimento da colaboração entre autores, este considerado um indicador do desenvolvimento de uma área; necessidade de periódicos interdisciplinares para escoamento da produção dos artigos arquivísticos; aumento do índice de autorias estrangeiras, que no período entre 2000 e 2007 alcançou índice de $28,75 \%$. O estudo ratifica alguns aspectos já apresentados por Jardim (1998), como a concentração geográfica do Rio de Janeiro nas autorias, a fragilidade da divulgação científica e a afinidade da Arquivologia com outras áreas do conhecimento para a publicação de artigos em periódicos.

Num outro trabalho publicado ainda no mesmo ano, a produção científica arquivística também foi analisada por Marques (2011) sob o prisma de sua interlocução com a Ciência da Informação $(\mathrm{Cl})$. A autora adotou como universo de pesquisa 45 dissertações e cinco teses oriundas de oito programas 
de pós-graduação em $\mathrm{Cl}$ de universidades brasileiras coletados no Banco de Teses da Capes. Foram mapeadas as referências bibliográficas arquivísticas, os autores, as obras de interesse da área, os países e idiomas de publicação. Das 5.260 referências identificadas, apenas 2.371 (45\%) mantinham relação com a arquivística ou com temáticas de interesse da área. Destas, foram encontradas em média $47,42 \%$ de referências arquivísticas por tese ou dissertação. Além disso, a Universidade Federal de Minas Gerais (UFMG) e a Universidade de Brasília (UnB) possuem as maiores concentrações de tais referências. Os países que possuem maiores frequências das referências bibliográficas são Brasil (1.419), França (203), Estados Unidos (164), Espanha (116) e Canadá (111). A língua portuguesa predominou como idioma de publicação, seja em versão original (1.239) ou traduzida (239). Os demais idiomas mapeados foram o inglês (444), espanhol (237), francês (182) e italiano (26). Geograficamente, foi identificada a procedência dos autores com mais obras referenciadas: cinco brasileiros (José Maria Jardim, Heloísa Bellotto, Ana Maria de Almeida Camargo, Célia Maria Leite Costa e Maria Odila Fonseca), dois norte-americanos (Michael Cook; Theodore Schellenberg) e um inglês (Charles Dollar). A partir da análise desses indicadores, a autora identificou o Brasil como o país em que prevaleceu a incidência de autores e obras nacionais, bem como o idioma português. A ocorrência de referências canadenses pode ser atribuída à influência da corrente teórica "Arquivística Integrada" que se fez presente nos anos 1980 e 1990. A hibridez advinda das demais contribuições internacionais, ao que tudo indica, favoreceu a interlocução da Arquivologia brasileira com outros países. O Brasil se destaca devido ao grande número de referências bibliográficas, o que reflete o crescente nível da produção científica arquivística nacional.

Ainda em 2011, a relação interdisciplinar entre a Arquivologia e a Ciência da Informação $(\mathrm{Cl})$ no Brasil foi o tema de pesquisa escolhido por Alexandre de Souza Costa e deu origem a dois dos trabalhos analisados. No primeiro, Costa (2011a) apresentou resultados parciais da pesquisa que desenvolvia no mestrado, quais sejam: a) a relação entre as disciplinas condiciona-se ao desenvolvimento de pesquisas que abordam aspectos teóricos e metodológicos da interdisciplinaridade entre as mesmas; b) a noção 
da informação arquivística aproximaria a Arquivologia da Ciência da Informação; c) a produção do conhecimento arquivístico nos programas de pós-graduação em Ciência da Informação possibilitou sua legitimação enquanto campo autônomo do conhecimento. Já no segundo, em sua dissertação de mestrado, Costa (2011b) apresentou o resultado final de sua dissertação. Seu objetivo foi analisar as seguintes publicações brasileiras lançadas entre 1995 e 2008: Jardim (1995, 1998), Rondinelli (2002), Santos (2002), Fonseca (2005), Silva (2008). Complementando os resultados obtidos pelo levantamento bibliográfico, realizaram-se entrevistas semiestruturadas com os autores das obras, exceto Maria Odila Fonseca, falecida em 2007. Seu objetivo era ter maior compreensão do interesse dos autores em pesquisa pela temática. Os resultados indicaram que: a) não houve regularidade na produção dos livros originados das teses e dissertações, já que o intervalo entre as publicações variou de forma inconstante; b) dois livros foram publicados no mesmo ano em que ocorreu a defesa da tese/dissertação e quatro publicados no ano seguinte; c) cinco livros foram publicados no Rio de Janeiro e um no Distrito Federal; d) a professora Maria Nélida González de Gómez possui três orientações das pesquisas, ao passo que os demais possuem uma orientação apenas (Regina Maria Marteleto, Georgete Medleg Rodrigues e José Maria Jardim); e) a editora comercial da Fundação Getúlio Vargas (FGV) e a editora da Universidade Federal Fluminense (UFF) publicaram dois livros cada enquanto que a Associação dos Arquivistas Brasileiros (AAB) e a Associação Brasiliense de Arquivologia (Abarq) publicaram um livro cada; f) os autores possuíam graduação nas áreas de Arquivologia e História; g) as principais temáticas abordadas eram a epistemologia arquivística, a gestão de documentos eletrônicos e as políticas públicas de informação arquivística; $h$ ) identificou-se incidências de citações ou referências nas bibliografias de autores da Ciência da Informação e da Arquivologia, tanto brasileiros quanto internacionais. Com relação às entrevistas, os autores dos livros responderam que:

- quanto ao tema das pesquisas, foram instigados pelas necessidades das práticas profissionais e dos desafios das atividades que desempenharam, além da questão do ineditismo do tema; 
- as pesquisas arquivísticas no campo da $\mathrm{Cl}$ foram atribuídas à necessidade de aproximação do objeto de pesquisa às propostas do programa, às possibilidades de diálogos entre as áreas, ao reconhecimento dos programas e à interdisciplinaridade;

- houve consenso ao afirmarem que realizariam atualmente suas pesquisas nos programas da Ciência da Informação;

- para os entrevistados, a subordinação da Arquivologia à Cl deuse por fatores políticos, ainda que seja reconhecida a autonomia da primeira;

- de forma geral, a repercussão dos livros foi mais notada a partir dos autores com seus pares, colegas e alunos do curso de Arquivologia;

- aspectos quanto às dificuldades da publicação foram apontados pelos entrevistados;

- também foi destacado o apoio de uma fundação de fomento à pesquisa, sem a qual um dos livros não teria sido publicado;

- sobre a baixa produção de livros em Arquivologia, os entrevistados atribuíram a inércia dos atores no campo arquivístico e à falta de incentivo das instituições;

- sobre a possibilidade de publicarem seus livros em versão eletrônica, caso ainda fossem inéditos, todos os entrevistados responderam "sim".

Para o autor, a Arquivologia, como área científica, está se desenvolvendo no Brasil, graças à produção de conhecimento difundida por meio de livros e pela quantidade de teses e dissertações, contribuindo para sua visibilidade legitimação. A maioria dos livros estudados estabeleceu diálogos com a Cl. Identificou-se três dimensões da pesquisa em $\mathrm{Cl}$ com temáticas arquivísticas: política, técnica e epistemológica.

O trabalho seguinte refere-se novamente à interação da Arquivologia com a Ciência da Informação (Cl), no qual Rodrigues (2012) analisou a produção arquivística através das comunicações disponíveis nos anais dos Encontros Nacionais de Pesquisa em Ciência da Informação (ENANCIB) entre 2003 e 2012. O autor pesquisou nos títulos dos trabalhos os termos "arquivologia”, "arquivística”, "arquivo” e "arquivista”, recuperando, assim, 54 trabalhos. De acordo com ele, 11 universidades e a Fundação Oswaldo Cruz (Fiocruz) produziram trabalhos com a temática. A formação dos pesquisadores 
incluem os cursos de História, Arquivologia e Biblioteconomia. Em seus resultados, foram relacionados os trabalhos da temática arquivística com as correntes teóricas da $\mathrm{Cl}$ e dos campos de pesquisa em arquivística, cujos dados foram apresentados em quadros que possuem as colunas do Grupo de Trabalho (GT), das palavras-chave e dos títulos. Por meio de suas análises, o autor inferiu que a Arquivologia vem forjando uma identidade no campo de produção do conhecimento e que há relação direta desta área com a $\mathrm{Cl}$. $\mathrm{A}$ presença de autores de trabalhos formados em Arquivologia é um reflexo do interesse de pesquisadores da área em produzirem pesquisas e apresentarem seus resultados no ENANCIB, que expõe a relação da Arquivologia com a Cl.

Um ano depois Santos Júnior (2013) pesquisou a relação entre a Arquivologia e os estudos bibliométricos e quantitativos. A intenção foi identificar a relação, ou a ausência, de estudos métricos no âmbito do escopo teórico ou prático da disciplina arquivística. $O$ autor realizou levantamento bibliográfico de diversos periódicos referentes ao período entre 1972 e 2011, além de revisão de literatura. Considerando apenas a literatura nacional, foram encontrados nove artigos em periódicos, duas comunicações em congresso e um livro que discutia ou utilizava tais métodos. Além dos trabalhos já abordados no presente estudo - Jardim (1998); Costa (2007); Pinto, Santos e Santos (2009); Medeiros, Nodare e Araújo (2010); Marques (2011); Bahia, Santos e Blattman (2011) - a pesquisa identificou:

- o artigo de Bomeny (1978), que, segundo o autor, foi o primeiro trabalho a tratar do tema, além de ser o único que utilizou métodos bibliométricos, no qual foram aplicadas a Lei de Lotka e do elitismo, na análise da correspondência particular de Getúlio Vargas no período entre 1930 e 1939;

- os trabalhos de Mariz $(2010,2011)$, citados com reservas pela utilização de análises webométricas para aferir o funcionamento, a inter-relação, a construção e o desenvolvimento das Instituições Arquivísticas Públicas Brasileiras na internet;

- a comunicação em evento de Fonseca (1999), apresentando dados quantitativos sobre localização de artigos e autores, procedência institucional dos artigos, temas dos artigos e local e origem dos autores institucionais;

- a comunicação em evento de Vilan Filho e Oliveira (2008), relato anterior da mesma pesquisa publicada em 2011 pelos mesmos 
autores e já analisado no presente estudo, que indicou o crescimento da produção científica da área e a dependência da Arquivologia de publicações interdisciplinares para disseminação de sua produção;

- o livro de Fonseca (2005), o único que utilizou métodos quantitativos em partes específicas da publicação para analisar a relação interdisciplinar entre a Arquivologia e a Ciência da Informação.

Por fim, além de ter encontrado pouca relação entre a Arquivologia e os estudos métricos, o autor quase não percebeu a aplicação de tais métodos em acervos documentais. Além disso, notou-se a baixa frequência de autores ligados diretamente à Arquivologia. Em última instância, esse trabalho comprova os resultados de diferentes pesquisas, relacionados a alguns fatos da produção científica arquivística: a baixa produção intelectual da área, as limitações teóricas e práticas da Arquivologia e sua inter-relação com outras áreas científicas, em especial, com a Ciência da Informação.

No mesmo ano foi publicado o trabalho de Pupim e Madio (2013) em que o periódico Arquivo \& Administração foi objeto de análise métrica realizada em 33 artigos científicos compreendidos entre os anos de 1972 e 1999. As pesquisadoras procuraram mapear a produtividade dos autores, a colaboração, as citações, os idiomas e os autores mais citados. A escolha por esse canal atribuiu-se ao fato de ser uma das publicações mais antigas da área e pelas autoras acreditarem que ele representava a evolução das pesquisas científicas em arquivística nas últimas décadas. Foram identificadas 412 citações no universo da pesquisa. A autoria única somou 29 artigos frente a quatro produzidos em coautoria. Com relação às citações, as autoras concluíram que: a) apenas 29 citações, das 412 totais, foram produzidas em coautoria (7\%); b) os idiomas com maior incidência nas referências são o português (70\%) e o inglês (14\%); as localizações geográficas com índices mais expressivos são Rio de Janeiro (33\%), São Paulo (14\%), Paris (11\%) e Brasília (10\%). Para identificação dos autores mais citados, foi considerada a incidência de pelo menos duas citações. Os autores mais citados são Schellenberg (12 vezes) e José Maria Jardim (oito vezes). De acordo com a metodologia adotada, constatou-se a prevalência da autoria única em relação à coautoria, o que 
indica que, neste caso, o trabalho solitário ainda é uma preferência dos pesquisadores da área arquivística. O Rio de Janeiro também concentra respeitável número de referências dos artigos analisados, fato este que pode estar relacionado à existência de instituições e cursos arquivísticos no Estado.

Publicado no ano seguinte, a identificação dos temas abordados na área de Arquivologia em periódicos de Ciência da Informação (Cl) foi pesquisada por Padilha e Rodrigues (2014). Como objetivos secundários, as autoras levantaram quais periódicos possuíam maior representatividade na área arquivística, a identificação dos autores mais produtivos e a classificação da produção de acordo com os nove campos de pesquisa na Arquivologia definidos pelos autores Couture, Martineau e Ducharme (1999), a saber: objeto e finalidade da arquivística; arquivos e sociedade; história dos arquivos e da arquivística; funções arquivísticas; gestão dos programas e dos serviços de arquivo; tecnologias; suportes e tipos de arquivo; meio profissional dos arquivos; e problemas particulares relativos aos arquivos. Foi criado o tópico "outros" para agrupar artigos que não se enquadraram nos campos acima. Excluíram-se os periódicos cujas atividades foram encerradas. Os dados foram coletados na Base de Dados Referencial de Artigos de Periódicos em Ciência da Informação (BRAPCl). Nos 19 periódicos científicos em circulação no período entre 1972 e 2010 foram recuperados 223 artigos dos quais apenas 144 continham os parâmetros estabelecidos pelas autoras. Os resultados demonstraram que as revistas que mais publicaram artigos na temática foram Arquivo \& Administração e Ponto de Acesso, com 36 e 12 artigos, respectivamente. A maior parte dos autores possuem doutorado e são oriundos do Programa de Pós-graduação em Ciência da Informação da Universidade Federal de Minas Gerais (UFMG). Embora haja variedade de temas em arquivística, eles são publicados em diferentes periódicos. De acordo com os dados, identificou-se forte oscilação na primeira década dos anos 2000, cujos maiores índices de produção ocorreram nos anos de 2006, com 20 artigos, e em 2007, com 18 artigos. Houve também variação no período estudado (19722010), com intensa produção em meados dos anos 2000: 20 artigos, em 2006, e 18 artigos, em 2007. Verificou-se o total de 192 autores no universo, sendo que os mais produtivos foram: Daniel Flores e José Maria Jardim, com seis 
artigos cada um. O número de autores com publicação igual ou superior a dois artigos foi de 33. Outro resultado importante foi a constatação de que a maior parte dos artigos não se enquadrava nos campos de pesquisa proposta por Couture, Martineau e Ducharme. A pesquisa demonstrou, ainda, que há diversificação dos temas publicados e que existe dispersão dos artigos em diferentes periódicos de outras áreas. Chama atenção o fato de muitos autores possuírem doutorado em Ciência da Informação, o que pode ser explicado pela ausência dos cursos de pós-graduação neste nível em Arquivologia.

A configuração da produção científica arquivística indexada nas bases de dados internacionais Scopus e Web of Science foi objeto de estudo de Silva e Caregnato (2014). As autoras utilizaram termos como "archival science", "archivist", "archivist", "records management", "record management" e "record manager" que designassem a área de Arquivologia e o profissional arquivista nos títulos, palavras-chave e resumo, sem limitação temporal ou de idioma. Adotou-se como indicadores de avaliação da referida produção o país, a área do periódico e o ano de publicação. Com base nesses parâmetros, as autoras obtiveram como ocorrências de artigos: 2.153 na base Scopus (36,2\% dos Estados Unidos e 9,43\% da Inglaterra), e 955 na Web of Science (35,39\% dos Estados Unidos e 11,94\% da Inglaterra), cujos índices revelaram os países mais recorrentes em relação à produção de artigos. As décadas de 1940 e 1950 foram as que apresentaram as maiores taxas de crescimento, 366,7\% e $2.100 \%$, respectivamente, nas bases Scopus e Web of Science, cujos períodos inserem-se na origem do records management, que surgiu nos Estados Unidos no pós-guerra, época do surgimento da explosão documental. A procedência das áreas e categorias da produção científica arquivística indicam a predominância das Ciências Sociais, História e Ciência da Computação. Foram identificados, ainda, em relação ao número de periódicos, 159 títulos na Scopus e 363 na Web of Science. O periódico com maior concentração em ambas as bases foi o American Archivist. A indexação de artigos brasileiros ocorreu da seguinte forma: 22 artigos entre os anos de 1996 e 2013 na Scopus e 13 artigos no período de 2007 a 2013 na Web of Science. Os resultados obtidos pela pesquisa revelaram, de modo geral, crescimento na publicação de artigos na área a partir da década de 1990, cujos índices foram verificados nos 
registros de ambas as bases consultadas. Outro importante fato observado pelas autoras foi o baixo índice de publicações resultantes de teses $\mathrm{e}$ dissertações. Comparativamente aos índices internacionais indexados nas bases de dados consultadas, ainda é pequeno o número de artigos com procedência brasileira.

Finalmente, e ainda no mesmo ano, a análise de citação feita por meio de estudo bibliométrico, referente às temáticas arquivísticas "classificação" e "descrição" nos periódicos Arquivo \& Administração e Archival Science (20012012), foi publicada por Silva, Rego, Guimarães e Tognoli (2014). A rede de citação foi construída no software Unicet a partir da presença dos termos "classificação/classification" e "descrição/description" nas palavraschave/keywords. A busca recuperou 51 artigos no periódico Arquivo \& Administração, dos quais apenas seis possuíam os temas de interesse; e 218 artigos no Archival Science, dos quais havia oito relacionados aos objetos em estudo. Dos 14 artigos analisados, três referiam-se à classificação (21\%) e 11 à descrição (79\%). No caso do Arquivo \& Administração, a autoria única prevaleceu em dez artigos $(71,43 \%)$, sendo que apenas quatro $(28,57 \%)$ possuíam dois ou mais autores, reflexo de uma tendência nas Ciências Humanas e Sociais. Em relação ao Archival Science, o índice de autorias múltiplas foi três vezes maior do que na revista brasileira. Comparando-se os dois periódicos, percebe-se discrepância relacionada à colaboração. Analisando-se a procedência das autorias, nota-se que, no caso brasileiro, há uma hegemonia de autores nacionais, ao passo que a Archival Science possui maior diversidade de procedência de autorias, fato que pode ser justificado pela predominância da língua inglesa e das diferentes nacionalidades do corpo editorial e do fácil acesso aos artigos. Desconsiderando-se a autocitação, os pesquisadores identificaram uma rede de citação com a presença de 38 autores citados em pelo menos dois artigos. Deste grupo, os que possuíam as maiores médias de citações por artigo são: Terry Cook (4,3 citações/autor), Elizabeth Yakel (4 citações/autor), Luciana Duranti (2,7 citações/autor) e A. Bawarshi (2,5 citações/autor). Os dados da pesquisa revelam, ainda, que o Canadá (53\%) e os Estados Unidos (47\%) são os países que concentraram a nacionalidade dos autores mais citados. A análise da rede de citações 
evidenciou que os autores internacionais possuíam maior articulação, enquanto que na realidade brasileira o comportamento predominante ainda era o trabalho desenvolvido isoladamente. Os dados da pesquisa indicaram também que a colaboração para o desenvolvimento de pesquisas no Brasil é pequena quando comparada aos índices internacionais. No caso brasileiro, parece prevalecer a autoria nacional nos artigos analisados.

\section{RESULTADOS}

O Quadro 1 apresenta as principais características dos 15 estudos analisados, onde podemos observar os aspectos relativos às autorias, tipo de publicação, tipo de análise realizada, os tipos e quantidades de documentos analisados, bem como os períodos, as fontes dos dados e o âmbito (nacional ou mundial). 
José Mauro Gouveia de Medeiros, Jayme Leiro Vilan Filho

Análise da produção científica da arquivologia no Brasil: uma revisão de literatura

Quadro 1 - Os estudos sobre literatura de Arquivologia e suas características (ordem cronológica

\begin{tabular}{|c|c|c|c|c|c|c|c|c|c|}
\hline & Autor & Ano & Afiliação & TP & TA & Doc. & Período & $\begin{array}{l}\text { Fonte } \\
\text { Dados }\end{array}$ & Âmbito \\
\hline 1 & Jardim & 1998 & UFF & $A$ & $\mathrm{Pr}$ & $67 \mathrm{~A}$ & $\begin{array}{c}1990 / 1995 \\
6 \text { anos }\end{array}$ & $\begin{array}{c}14 \\
\text { periódicos }\end{array}$ & Brasil \\
\hline 2 & Costa,A & 2007 & UNIRIO & $A$ & $\mathrm{Pr}$ & $77 \mathrm{~L}$ & $\begin{array}{c}1960 / 2006 \\
47 \text { anos }\end{array}$ & $\begin{array}{c}4 \\
\text { bibliotecas }\end{array}$ & Brasil \\
\hline 3 & $\begin{array}{l}\text { Pinto } \\
\text { Santos, R } \\
\text { Santos,E }\end{array}$ & 2009 & $\begin{array}{l}\text { UFSC } \\
\text { UFSC } \\
\text { UFSC }\end{array}$ & $A$ & $\mathrm{Ci}$ & $\begin{array}{c}27 \mathrm{~A} \\
461 \\
\mathrm{R}\end{array}$ & $\begin{array}{c}2005 / 2007 \\
3 \text { anos }\end{array}$ & $\begin{array}{l}\text { Arquiv.net } \\
\text { (1 } \\
\text { periódico) }\end{array}$ & Brasil \\
\hline 4 & $\begin{array}{l}\text { Medeiros } \\
\text { Nodare } \\
\text { Araújo }\end{array}$ & 2010 & $\begin{array}{l}\text { UFMG } \\
\text { UFMG } \\
\text { UFMG }\end{array}$ & $A$ & $\begin{array}{l}\mathrm{Pr} \\
\mathrm{Ci}\end{array}$ & $\begin{array}{c}21 \mathrm{~A} \\
394 \\
\mathrm{R} \\
\end{array}$ & $\begin{array}{c}2004 / 2006 \\
3 \text { anos }\end{array}$ & $\begin{array}{c}\text { Arq.\&Adm. } \\
(1 \\
\text { periódico) }\end{array}$ & Brasil \\
\hline 5 & $\begin{array}{l}\text { Bahia } \\
\text { Santos, R } \\
\text { Blatmann }\end{array}$ & 2011 & $\begin{array}{l}\text { UFSC } \\
\text { UFPE } \\
\text { UFSC }\end{array}$ & $A$ & $\mathrm{Pr}$ & $\begin{array}{c}1750 \\
\mathrm{~A}\end{array}$ & $\begin{array}{c}1975 / 2009 \\
35 \text { anos }\end{array}$ & LISA & $\begin{array}{c}\text { Preserv. } \\
\text { Digital } \\
\text { (Mundo) }\end{array}$ \\
\hline 6 & $\begin{array}{l}\text { Vilan Fo } \\
\text { Oliveira }\end{array}$ & 2011 & $\begin{array}{l}\text { UNB } \\
\text { UNB }\end{array}$ & $A$ & $\mathrm{Pr}$ & $\begin{array}{c}143 \\
A\end{array}$ & $\begin{array}{c}1972 / 2007 \\
33 \text { anos }\end{array}$ & $\begin{array}{c}\text { Arq.\&Adm. } \\
\text { Arquiv.net } \\
\text { (2 } \\
\text { periódicos) }\end{array}$ & Brasil \\
\hline 7 & Marques & 2011 & UNB & $A$ & $\mathrm{Ci}$ & $\begin{array}{c}50 \\
\text { TD } \\
2371 \\
\mathrm{R}\end{array}$ & $\begin{array}{c}1986 / 2006 \\
21 \text { anos }\end{array}$ & $\begin{array}{c}\text { PPGCl } \\
\text { (Capes) }\end{array}$ & Brasil \\
\hline 8 & Costa,A & 2011 & UFF & $A$ & $\mathrm{Pr}$ & $6 \mathrm{~L}^{*}$ & $\begin{array}{c}1995 / 2008 \\
4 \text { anos }\end{array}$ & PPGCI & Brasil \\
\hline 9 & Costa,A & 2011 & UFF & $\mathrm{D}$ & $\mathrm{Pr}$ & $6 \mathrm{~L}^{*}$ & $\begin{array}{c}1995 / 2008 \\
14 \text { anos }\end{array}$ & PPGCI & Brasil \\
\hline 10 & Rodrigues, V & 2012 & UFRGS & $\mathrm{M}$ & $\mathrm{Pr}$ & $54 E$ & $\begin{array}{c}2003 / 2012 \\
10 \text { anos }\end{array}$ & ENANCIB & Brasil \\
\hline 11 & Santos Jr & 2013 & $\begin{array}{l}\text { IBICT/ } \\
\text { UFRJ }\end{array}$ & $A$ & $\mathrm{Pr}$ & $\begin{array}{c}9 \mathrm{~A} \\
2 \\
\mathrm{E}, 1 \\
\mathrm{~L}\end{array}$ & $\begin{array}{c}1972 / 2011 \\
40 \text { anos }\end{array}$ & $\begin{array}{c}12 \\
\text { periódicos }\end{array}$ & $\begin{array}{c}\text { Metrias } \\
\text { Brasil }\end{array}$ \\
\hline 12 & $\begin{array}{l}\text { Pupim } \\
\text { Madio }\end{array}$ & 2013 & $\begin{array}{l}\text { UNESP } \\
\text { UNESP }\end{array}$ & $E$ & $\begin{array}{l}\mathrm{Pr} \\
\mathrm{Ci}\end{array}$ & $\begin{array}{c}33 \mathrm{~A} \\
412 \\
\mathrm{R}\end{array}$ & $\begin{array}{c}1972 / 2009 \\
38 \text { anos }\end{array}$ & $\begin{array}{c}\text { Arq.\&Adm. } \\
\text { (1 } \\
\text { periódico) }\end{array}$ & Brasil \\
\hline 13 & $\begin{array}{l}\text { Padilha } \\
\text { Rodrigues, } R\end{array}$ & 2014 & $\begin{array}{l}\text { UFSC } \\
\text { UFSC }\end{array}$ & $A$ & $\mathrm{Pr}$ & $\begin{array}{c}144 \\
\mathrm{~A}\end{array}$ & $\begin{array}{c}1972 / 2010 \\
39 \text { anos }\end{array}$ & $\begin{array}{c}\text { Brapci } \\
19 \\
\text { periódicos }\end{array}$ & Brasil \\
\hline 14 & $\begin{array}{l}\text { Silva,R } \\
\text { Caregnato }\end{array}$ & 2014 & $\begin{array}{l}\text { UFRGS } \\
\text { UFRGS }\end{array}$ & $E$ & $\mathrm{Pr}$ & $\begin{array}{c}2135 \\
\text { A } \\
955 \\
\text { A }\end{array}$ & $\begin{array}{c}1934 / 2014 \\
81 \text { anos }\end{array}$ & $\begin{array}{c}\text { WoS } \\
\text { Scopus }\end{array}$ & Mundo \\
\hline 15 & $\begin{array}{l}\text { Silva,A } \\
\text { Rego } \\
\text { Guimarães } \\
\text { Tognoli }\end{array}$ & 2014 & $\begin{array}{l}\text { UNESP } \\
\text { UNESP } \\
\text { UNESP } \\
\text { UNESP }\end{array}$ & $E$ & $\begin{array}{r}\mathrm{Re} \\
\mathrm{Ci}\end{array}$ & $14 \mathrm{~A}$ & $\begin{array}{c}2001 / 2012 \\
12 \text { anos }\end{array}$ & $\begin{array}{l}\text { Arq.\&Adm. } \\
\text { Archival } \\
\text { Science } \\
\text { (2 } \\
\text { periódicos) }\end{array}$ & $\begin{array}{l}\text { Classific. } \\
\text { Descrição }\end{array}$ \\
\hline
\end{tabular}

Fonte: o próprio autor. Onde: $\left(^{*}\right)$ livros originados de teses; TP = tipo de publicação, TA = tipo de análise, $\mathrm{Pr}=$ produção, $\mathrm{Ci}=$ citação, $\mathrm{Re}=$ redes, $\mathrm{A}=$ artigos, $\mathrm{L}=$ livros, $\mathrm{D}=$ dissertação, TD $=$ tese ou dissertação, $T$ = trabalhos de eventos, $M=$ monografia, $R=$ referências, $P P G C l=$ Programas de Pós-Graduação em Ciência da Informação, WoS = Web of Science, Arq.\&Adm = Arquivo\&Administração; Arquiv.net = Arquivística. net . 
José Mauro Gouveia de Medeiros, Jayme Leiro Vilan Filho

Análise da produção científica da arquivologia no Brasil: uma revisão de literatura

Já os Quadros 2a e 2b apresentam os principais resultados dos estudos, destacando os aspectos relacionados com: os documentos analisados, os aspectos relacionados com as referências das citações, os aspectos temáticos, entre outros.

Quadro 2a - Os estudos e seus principais resultados (ordem cronológica)

\begin{tabular}{|c|c|c|c|}
\hline & Autor & Período & Resultados Destacados \\
\hline 1 & Jardim & $\begin{array}{l}1990 \\
1995\end{array}$ & $\begin{array}{l}\text { Produção: } 7,8 \text { doc./ano concentrados no RJ, } 35 \% \text { em coautoria; } 51 \% \\
\text { publicados em periódicos de organizações arquivísticas. Temas: } 25 \% \\
\text { tecnologia aplicada, } 13 \% \text { políticas arquivísticas, } 13 \% \text { "classificação, } \\
\text { arranjo e descrição", } 11 \% \text { teoria arquivística. }\end{array}$ \\
\hline 2 & Costa,A & $\begin{array}{l}1960 \\
2006\end{array}$ & $\begin{array}{l}\text { Autores que mais publicaram: Heloísa Bellotto, Ana Maria Camargo, } \\
\text { José Maria Jardim e Luís Carlos Lopes com } 4 \text { livros. } 66,2 \% \text { eram } \\
\text { manuais. Observado crescimento quali e quantitativo da produção } \\
\text { brasileira; necessidade de pesquisas em nível de PG. }\end{array}$ \\
\hline 3 & $\begin{array}{l}\text { Pinto } \\
\text { Santos,R } \\
\text { Santos, E }\end{array}$ & $\begin{array}{l}2005 \\
2007\end{array}$ & $\begin{array}{l}\text { Artigos: } 44 \% \text { em coautoria. Referências: autorias } 68 \% \text { única, } 21 \% \\
\text { coautoria e } 11 \% \text { institucionais; } 36 \% \text { livros, } 34 \% \text { artigos; } 68 \% \text { em } \\
\text { português, } 21 \% \text { em inglês, } 9 \% \text { espanhol; vida média de } 4 / 5 \text { anos; } 17 \% \\
\text { estrangeiras ( } 20 \% \text { Portugal, } 20 \% \text { Espanha, } 14 \% \text { Canadá, } 10 \% \text { França) } \\
\text { e } 83 \% \text { brasileiras ( } 30 \% \text { RJ, } 10 \% \text { SP, } 7 \% \text { DF). }\end{array}$ \\
\hline 4 & $\begin{array}{l}\text { Medeiros } \\
\text { Nodare } \\
\text { Araújo }\end{array}$ & $\begin{array}{l}2004 \\
2006\end{array}$ & $\begin{array}{l}\text { Correntes teóricas de } \mathrm{Cl}: 43 \% \text { Teoria Sistêmica, } 19 \% \\
\text { Representação/Classificação, } 19 \% \text { Estudos de Usuários, } 14 \% \text { Redes e } \\
\text { Fluxos Informação, } 5 \% \text { Teoria Crítica. } 24 \text { autores: } 63 \% \text { Brasileiros e } \\
33 \% \text { estrangeiros. Referências: média } 19 / \text { art., } 48 \% \text { nacionais e } 52 \% \\
\text { estrangeiras. }\end{array}$ \\
\hline 5 & $\begin{array}{l}\text { Bahia } \\
\text { Santos, R } \\
\text { Blatmann }\end{array}$ & $\begin{array}{l}1975 \\
2009\end{array}$ & $\begin{array}{l}85,9 \% \text { dos artigos sobre a preservação digital estão em } 60(39 \%) \text { dos } \\
153 \text { periódicos. }\end{array}$ \\
\hline 6 & $\begin{array}{l}\text { Vilan Fo } \\
\text { Oliveira }\end{array}$ & $\begin{array}{l}1972 \\
2007\end{array}$ & $\begin{array}{l}\text { Produção: cai nas décadas de } 1980 \text { e } 1990 \text {, cresce a partir dos anos } \\
2000 ; 66 \% \text { no RJ, } 22 \% \text { estrangeiras, } 14 \% \text { no DF e } 11 \% \text { em SP; cresce } \\
\text { coautoria (32\% de 2001-2007), cresce autoria estrangeira ( } 29 \% \text { em } \\
2000-2007 \text { ). Maior abrangência geográfica das autorias. Dependência } \\
\text { de publicações interdisciplinares. }\end{array}$ \\
\hline 7 & Marques & $\begin{array}{l}1986 \\
2006\end{array}$ & $\begin{array}{l}\text { Referências: } 47,42 \% \text { por documento; UFMG e UnB mais citadas; } \\
62,33 \% \text { em português ( } 52,25 \% \text { originais e } 10,08 \% \text { traduções); } 90 \\
\text { autores brasileiros e } 89 \text { estrangeiros; mais referenciados: José Maria } \\
\text { Jardim ( } 7 \text { ), Heloísa Bellotto (3) Ana Maria A. Camargo (3) e Célia Maria } \\
\text { L. Costa (3). A hibridez da influência internacional de tradições práticas } \\
\text { e teóricas favorecem os avanços internacionais da área. Necessidade } \\
\text { de cursos de mestrado e doutorado na área. }\end{array}$ \\
\hline 8 & Costa,A & $\begin{array}{l}1995 \\
2008\end{array}$ & $\begin{array}{l}\text { O livro tem papel de destaque. Interdisciplinaridade entre a } \\
\text { Arquivologia e a Cl submete-se pesquisas que estudem } \\
\text { interdisciplinaridade entre as disciplinas, especialmente em PPGCI. A } \\
\text { noção de informação arquivística aproxima a Arquivologia da Cl. }\end{array}$ \\
\hline
\end{tabular}

Fonte: o próprio autor.

Notas: $\left({ }^{*}\right)$ inclui artigos, relatos de exp. e comunicações $\left({ }^{* *}\right)$ livros originados de teses; Onde: $\mathrm{TO}=$ tipo de obra, $\mathrm{TA}=$ tipo de Análise, $\mathrm{Pr}=$ Produção, $\mathrm{Ci}=$ Citação, $\mathrm{Re}=$ redes, $\mathrm{AU}=$ autoria única, $A M=$ autoria múltipla, $A=$ artigos, $L=$ livros, $D=$ dissertação, $T D=$ tese ou dissertação, $T$ = trabalhos de eventos, $\mathrm{M}=$ monografia, $\mathrm{R}=$ referências, $\mathrm{PPGCl}=$ Programas de PósGraduação em Ciência da Informação, Est. Metr. = estudos métricos, WoS = Web of Science, $E U A=$ Estados Unidos da América, $\mathrm{RU}=$ Reino Unido. 
José Mauro Gouveia de Medeiros, Jayme Leiro Vilan Filho

Análise da produção científica da arquivologia no Brasil: uma revisão de literatura

Quadro $\mathbf{2 b}$ - Os estudos e seus principais resultados (ordem cronológica)

\begin{tabular}{|c|c|c|c|}
\hline & Autor & Período & Resultados Destacados \\
\hline 9 & Costa,A & $\begin{array}{l}1995 \\
2008\end{array}$ & $\begin{array}{l}\text { Produção baixa e irregular de livros de teses que cresce a partir } \\
\text { década de } 2000 \text {. Importância das editoras universitárias. } \\
\text { Preponderância dos diálogos com Cl. Dimensões: política, técnica e } \\
\text { epistêmica. } 5 \text { livros publicados no RJ e um no DF. Predomínio de } \\
\text { autores acadêmicos. Constata busca de diálogos entre a Cl e } \\
\text { Arquivologia com inter-relação ocorrendo de forma mais multidisciplinar } \\
\text { que interdisciplinar. }\end{array}$ \\
\hline 10 & $\begin{array}{l}\text { Rodrigues, } \\
\text { V }\end{array}$ & $\begin{array}{l}2003 \\
2012\end{array}$ & $\begin{array}{l}\text { Maior produção UnB (13), Unirio (9) e Unesp (8), maioria de } \\
\text { pesquisadores de PPG. Cursos de graduação ajudaram a forjar } \\
\text { identidade da Arquivologia. ENANCIB contribui para o avanço de } \\
\text { pesquisa. Há relação direta da Arquivologia com Cl. }\end{array}$ \\
\hline 11 & Santos Jr & $\begin{array}{l}1972 \\
2011\end{array}$ & $\begin{array}{l}\text { Poucos trabalhos sobre Arquivologia e estudos métricos; poucos } \\
\text { autores ligados diretamente com a Arquivologia e baixa produção da } \\
\text { área. }\end{array}$ \\
\hline 12 & $\begin{array}{l}\text { Pupim } \\
\text { Madio }\end{array}$ & $\begin{array}{l}1972 \\
2009\end{array}$ & $\begin{array}{l}\text { Artigos: } 22 \% \text { em coautoria; citações: } 07 \% \text { em coautoria, } 70 \% \text { em } \\
\text { português e } 14 \% \text { em inglês; } 33 \% \text { do RJ, } 14 \% \text { de SP, } 11 \% \text { de Paris, } \\
10 \% \text { do DF; } 49 \% \text { livros e } 25 \% \text { periódicos e seus artigos; autores mais } \\
\text { citados: Schellemberg e Jardim. }\end{array}$ \\
\hline 13 & $\begin{array}{l}\text { Padilha } \\
\text { Rodrigues, } \\
\text { R }\end{array}$ & $\begin{array}{l}1972 \\
2010\end{array}$ & $\begin{array}{l}\text { Arquivo\&Administração e Ponto de Acesso publicam mais; maior } \\
\text { produção em } 2006 \text { ( } 20 \text { artigos); } 192 \text { autores: } 33 \text { com } 2 \text { ou mais artigos; } \\
\text { maior produção: Daniel Flores (6) e José Maria Jardim (6); doutores da } \\
\text { UFMG se destacam; diversidade de temas; produção dispersa em } \\
\text { periódicos de outras áreas. }\end{array}$ \\
\hline 14 & $\begin{array}{l}\text { Silva,R } \\
\text { Caregnato }\end{array}$ & $\begin{array}{l}1934 \\
2014\end{array}$ & $\begin{array}{l}\text { A taxa de crescimento de artigos indexados em ambas as bases é } \\
\text { descontínua; American Archivist com maior número de artigos; baixa } \\
\text { visibilidade de artigos brasileiros: Scopus (22) e WoS (13); maior } \\
\text { visibilidade: EUA e RU; predominância de estudos relacionados à } \\
\text { gestão documental e à arquivística integrada; poucas pesquisas } \\
\text { oriundas de teses e dissertações no Brasil. }\end{array}$ \\
\hline 15 & $\begin{array}{l}\text { Silva,A } \\
\text { Rego } \\
\text { Guimarães } \\
\text { Tognoli }\end{array}$ & $\begin{array}{l}2001 \\
2012\end{array}$ & $\begin{array}{l}\text { Artigos sobre classificação }(21 \%) \text { e descrição }(79 \%) \text {. } 28,58 \% \text { em } \\
\text { coautoria; Archival Science tem mais coautorias; rede de citação: } 38 \\
\text { autores, estrangeiros são mais articulados e tem maiores médias de } \\
\text { citação: Terry Cook (4,3), Elizabeth Yakel (4). Necessidade de } \\
\text { investimento em pesquisas sobre classificação e descrição. }\end{array}$ \\
\hline
\end{tabular}

Fonte: o próprio autor. Notas: $\left({ }^{*}\right)$ inclui artigos, relatos de exp. e comunicações $\left({ }^{* *}\right)$ livros originados de teses; Onde: $\mathrm{TO}=$ tipo de obra, $\mathrm{TA}=$ tipo de Análise, $\mathrm{Pr}=$ Produção, $\mathrm{Ci}=$ Citação, $\mathrm{Re}=$ redes, $\mathrm{AU}=$ autoria única, $\mathrm{AM}=$ autoria múltipla, $\mathrm{A}=$ artigos, $\mathrm{L}=$ livros, $\mathrm{D}=$ dissertação, $T D=$ tese ou dissertação, $T=$ trabalhos de eventos, $M=$ monografia, $R=$ referências, $\mathrm{PPGCI}=$ Programas de Pós-Graduação em Ciência da Informação, Est. Metr. = estudos métricos, WoS $=$ Web of Science, $E U A=$ Estados Unidos da América, $R U=$ Reino Unido. 


\section{CONSIDERAÇÕES FINAIS}

Considerando a cobertura das fontes consultadas nesse estudo pode-se afirmar que o interesse pela literatura de Arquivologia está aumentando de forma significativa, especialmente a partir de 2007, e diversificando os canais de publicação, que passaram de exclusivamente artigos (1998-2010), para principalmente trabalhos de eventos e artigos a partir de 2013. Embora possuam uma variedade de fontes, o livro aparece com destaque como objeto citado nas referências de pesquisas conforme apresentado em Pinto, Santos e Santos (2009) e Pupim e Madio (2013). Os períodos analisados pelos estudos são bem diversificados, variando de 3 a 81 anos, abrangendo em sua maioria mais de dez anos de publicações relacionadas com o contexto arquivístico brasileiro.

Analisando as autorias dos 15 estudos selecionados pode-se notar que não há concentração significativa nem de autores, que somam 25 pessoas, nem nas instituições em que trabalham, com destaque para a UFSC e UNESP que somam quase metade (13) das 28 afiliações e $1 / 3$ do total de estudos. A concentração de poucos autores com índice de produtividade maior em relação aos que produziram apenas um artigo foi constatada nos trabalhos produzidos por Jardim (1998), Medeiros, Nodare e Araújo (2010), e Padilha e Rodrigues (2014). Em relação à colaboração no desenvolvimento de pesquisas arquivísticas, indicada pela coautoria, os índices vem crescendo ultimamente no país, ainda que o número de trabalhos em autoria única seja maior.

Os periódicos e seus artigos são os objetos de estudo preferidos, sejam acessados diretamente ou por meio de catálogos de bibliotecas ou bases de dados (nacionais ou internacionais), embora tenham sido observadas, também, pesquisas com livros, teses, dissertações e trabalhos de ENANCIB. Preponderaram as análises de produção científica, muitas vezes combinadas com análises de citação, ocorrendo apenas um estudo de rede (SILVA et al., 2014).

A relação científica da Arquivologia com a Ciência da Informação foi comprovada por meio dos estudos de Medeiros, Nodare e Araújo (2010), Marques (2011), Costa (2011a) e Rodrigues (2012), ainda que os objetos de estudo e os períodos analisados sejam distintos. Geograficamente, no Brasil, o Estado do Rio de Janeiro destaca-se como a região com maior índice de produção de conhecimento 
científico arquivístico, fato este apontado nos trabalhos de Jardim (1998), Pinto, Santos e Santos (2009), Vilan Filho e Oliveira (2011), Costa (2011b), e Pupim e Madio (2013).

O periódico Arquivo \& Administração figura com destaque nos resultados das pesquisas de Vilan Filho e Oliveira (2011), Pupim e Madio (2013), e Padilha e Rodrigues (2014), tendo sido ainda objeto de estudo nos trabalhos de Medeiros, Nodare e Araújo (2010), Pupim e Madio (2013), e Silva, Rego, Guimarães e Tognoli (2014). Esses dados revelam a importância que esse periódico possuía como canal de comunicação científica arquivística brasileira até o seu encerramento em 2015, decorrente da extinção da Associação dos Arquivistas Brasileiros que o editava.

Além de mostrar os diferentes aspectos sobre a literatura arquivística brasileira, o presente estudo mostra elementos suficientes para concluir que a Arquivologia se consolida cada vez mais no Brasil, com aumento de produção, colaboração e interesse na sua literatura científica, apesar da ausência de periódicos específicos. Em decorrência desta ausência, e principalmente do contexto acadêmico relacionado com os programas de pós-graduação é natural que os periódicos e eventos relacionados com a Ciência da Informação sejam amplamente usados como canais de disseminação do conhecimento arquivístico no Brasil.

Finalmente, é importante ressaltar também a importância das instituições públicas e das instituições federais de ensino superior que viabilizam o desenvolvimento de pesquisas arquivísticas, fomentando a produção do conhecimento científico da Arquivologia no Brasil.

\section{REFERÊNCIAS}

ALVARADO, Ruben U. Elitismo na literatura sobre a produtividade dos autores.

Ciência da Informação, Brasília, v. 38, n. 2, p. 69-79, maio/ago. 2009.

ARBOIT, Aline Elis; BUFREM, Leilah Santiago. Produção de trabalhos científicos em eventos nacionais da área de Ciência da Informação. In: HAYASHI, Maria Cristina Piumbato; MUGNAINI, Rogério; HAYASHI, Carlos Roberto Massao (Orgs.).

Bibliometria e Cientometria: metodologias e aplicações. São Carlos: Pedro \& João Editores, 2013. 
BAHIA, Eliana Maria dos Santos; SANTOS, Raimundo Nonato Macedo dos; BLATTMANN, Úrsula. Estudo bibliométrico sobre preservação digital: Library and Information Sciense Abstracts - LISA. Encontros Bibli: Revista Eletrônica de Biblioteconomia e Ciência da Informação, Florianópolis, n. esp., $1^{\circ}$ sem. 2011.

BASE DE DADOS REFERENCIAL DE ARTIGOS DE PERIÓDICOS EM CIÊNCIA DA INFORMAÇÃO/BRAPCI. Disponível em: <http://www.brapci.ufpr.br>. Acesso em: 29 abr. 2015.

BOMENY, Regina Helena Diniz. Estudo bibliométrico aplicado ao arquivo privado de Getúlio Vargas. Ciência da Informação, Brasília, v. 7, n. 1, p. 37-42, 1978.

CORREA, Edilson José; VASCONCELOS, Mara; SOUZA, Maria Suzana de Lemos. Iniciação à metodologia científica: participação em eventos e elaboração de textos científicos. Belo Horizonte: Nescon UFMG, Coopmed, 2009.

CÔRTES, Pedro Luiz. Considerações sobre a evolução da ciência e da comunicação científica. In: POBLACION, Dinah Aguiar; WEBER, Geraldina Porto; SILVA, José Fernando Modesto da (Orgs). Comunicação e produção científica: contexto, indicadores, avaliação. São Paulo: Angellara, 2006.

COSTA, Alexandre de Souza. A bibliografia arquivística no Brasil - Análise quantitativa e qualitativa. Arquivística.net, Rio de Janeiro, v. 3, p. 8-26, jan./jun. 2007.

COSTA, Alexandre de Souza. Produção de conhecimento em Arquivologia ou em Ciência da Informação? Uma análise a partir dos livros em Arquivologia originados de teses e dissertações em Ciência da Informação no Brasil. Revista Edicic, v. 1, n. 4, p. 175-187, out./dez. 2011a.

COSTA, Alexandre de Souza. Produção de conhecimento em Arquivologia sob a égide dos programas de pós-graduação em Ciência da Informação. 2011. 137 f. Dissertação (Mestrado em Ciência da Informação). Universidade Federal Fluminense, Niterói, 2011b.

COUTURE, Carol; MARTINEAU, Jocelyne; DUCHARME, Daniel. A formação e a pesquisa em Arquivísitica no mundo contemporâneo. Trad. Luís Carlos Lopes; Brasília: Finatec, 1999.

FONSECA, Maria Odila Kahl. Formação e capacitação profissional e a produção do conhecimento arquivístico. 1999. Disponível em: <http://www.conarq.arquivonacional.gov.br/Media/publicacoes/mesa/formao_e_capa citao_profissional_e_a_produo.pdf>. Acesso em: 30 jun. 2015.

FONSECA, Maria Odila Kahl. Arquivologia e Ciência da Informação. Rio de Janeiro: Editora da Fundação Getúlio Vargas, 2005. 
JARDIM, José Maria. Sistemas e políticas públicas de arquivos no Brasil. Niterói, RJ: EDUFF, 1995.

JARDIM, José Maria. A produção de conhecimento arquivístico: perspectivas internacionais e o caso brasileiro (1990-1995). Ciência da Informação, Brasília, v. 27, n. 3, 1998.

JARDIM, José Maria. Transparência e opacidade do Estado no Brasil: usos e desusos da informação governamental. Niterói, RJ: Editora da Universidade Federal Fluminense, 1999.

MARIZ, Anna Carla Almeida. Arquivos Públicos Brasileiros: análise da evolução da transferência da informação arquivística na internet. Encontros Bibli: Revista Eletrônica de Biblioteconomia e Ciência da Informação, Florianópolis, n. esp., $1^{\circ}$ sem, 2011.

MARIZ, Anna Carla Almeida. Arquivos Públicos Brasileiros: estudo dos processos de transferência da informação na internet e sua evolução. Arquivo \& Administração, Rio de Janeiro, v. 9, p. 55-72, 2010.

MARQUES, Angelica Alves da Cunha. Pesquisas com temáticas arquivísticas na Ciência da Informação: mapeamento das principais tendências. Encontros Bibli: Revista Eletrônica de Biblioteconomia e Ciência da Informação, Florianópolis, n. esp., $1^{\circ}$ sem, 2011.

MEADOWS, Arthur Jack. A comunicação científica. Brasília: Briquet de Lemos, 1999.

MEDEIROS, Nilcéia Lage; NODARE, Thaís; ARAÚJO, Carlos Alberto Ávilla. As relações do conhecimento produzido na área de arquivologia com a ciência da informação. Ciência da Informação, Brasília, v. 39, n. 2, p. 44-53, maio/ago. 2010.

MUELLER, Suzana Pinheiro Machado. A publicação da ciência: áreas científicas e seus canais preferenciais. DataGramaZero, v. 6, n. 1, fev. 2005.

MUELLER, Suzana Pinheiro Machado; CAMPELLO, Bernadete Santos; DIAS, Eduardo Wense. Disseminação da pesquisa em ciência da informação e biblioteconomia no Brasil. Ciência da Informação, v. 25, n. 3, 1996.

PADILHA, Débora de Meira; RODRIGUES, Rosângela Schwarz. A temática arquivística: estudos das publicações nos periódicos da Ciência da Informação. Ágora, Florianópolis, v. 24, n. 49, p. 25-56, 2014.

PINTO, Marli Dias de Souza; SANTOS, Raimundo Nonato Macedo dos; SANTOS, Eliana Maria Bahia dos. Análise de citação da revista eletrônica Arquivística.net: uma aplicação das técnicas bibliométricas. Em Questão, v. 15, p. 27-41, 2009. 
PRICE, Derek J. de Solla. O desenvolvimento da ciência: análise histórica, filosófica, sociológica e econômica. Tradução de Simão Mathias e Gilda Maria Braga. Rio de Janeiro: Livros Técnicos e Científicos, 1976.

PUPIM, Eliana Kátia; MADIO, Telma Campanha de Carvalho. Periódico Arquivo \& Administração: reflexões a partir de uma análise métrica. In: ENCONTRO NACIONAL DE PESQUISA EM CIÊNCIA DA INFORMAÇÃO, 14., Florianópolis. Anais..., 2013. Disponível em:

<http://enancib2013.ufsc.br/index.php/enancib2013/XIVenancib/paper/view/399>. Acesso em: 1 abr. de 2015.

RODRIGUES, Vander Luís Duarte. Arquivologia e Ciência da Informação: uma análise da produção da área no Encontro Nacional de Ciência da Informação. 2012. Trabalho de Conclusão de Curso (Graduação em Arquivologia) - Universidade Federal do Rio Grande do Sul, Porto Alegre, 2012.

RONDINELLI, R. C. Gerenciamento arquivístico de documentos eletrônicos: uma abordagem teórica da diplomática arquivística contemporânea. Rio de Janeiro: FGV Editora, 2005.

SANTOS, Vanderlei Batista. Gestão de documentos eletrônicos: uma visão arquivística. Brasília: Abarq, 2002.

SANTOS JÙNIOR, Roberto Lopes dos. Análise sobre a (não) relação entre a Arquivologia e os estudos bibliométricos e quantitativos. DataGramaZero, v. 14, n. 2, abr, 2013.

SILVA, Andrielli Pachu da et al. A presença das temáticas classificação e descrição na literatura arquivística: uma análise de citação a partir dos periódicos Arquivo \& Administração e Archival Science (2001-2012). In: ENCONTRO BRASILEIRO DE BIBLIOMETRIA E CIENTOMETRIA, 4., Recife, 2014. Disponível em: <http://www.brapci.inf.br/_repositorio/2014/05/pdf_2ab08479b1_0014431.pdf> Acesso em: 1 abr. de 2015.

SILVA, Rita de Cássia Portela; CAREGNATO, Sonia Elisa. A atividade científica em Arquivologia: um estudo nas bases de dados Scopus e Web of Science. In: ENCONTRO BRASILEIRO DE BIBLIOMETRIA E CIENTOMETRIA, 4., Recife, 2014. Disponível em: <http://www.brapci.inf.br/_repositorio/2014/05/pdf_300e54447e_0014456.pdf>. Acesso em: 1 abr. 2015.

SILVA, Sérgio Conde de Albite. A preservação da informação arquivística governamental nas políticas do Brasil. Rio de Janeiro: Associação dos Arquivistas Brasileiros, 2008.

VILAN FILHO, Jayme Leiro; OLIVEIRA, Eliane Braga de. A produção de artigos nos periódicos científicos brasileiros de Arquivologia (1972-2006). In: CONGRESSO BRASILEIRO DE ARQUIVOLOGIA, 15., Goiânia, 2008. Anais... Goiânia, 2008. 
VILAN FILHO, Jayme Leiro; OLIVEIRA, Eliane Braga de. Periódicos científicos brasileiros de Arquivologia: os artigos e suas autorias (1972-2007). Revista IberoAmericana de Ciência da Informação, Brasília, v. 4, n. 2, p. 82-93, ago./dez. 2011.

\title{
Title
}

Analysis of scientific production archival science in brazil: a literature review

\begin{abstract}
Introduction: review of the literature resulting from bibliographic survey about the scientific literature of archives in Brazil.

Objective: to identify aspects of scientific literature of archival science, through bibliographical research, that aims to introduce the features of the archival science in Brazil.

Methodology: Brazilian sites, databases and reference services were used as sources to identify 523 references. 15 texts were selected and analyzed with respect to authorship, affiliation, publication year, publication type, type and size of sources used, methodology, geographical range, results, among other aspects.

Results: the scientific articles were the main object of study; the book was the most cited channel; the journal Arquivo \& Administração and Encontro Nacional de Pesquisa em Ciência da Informação have importance on the national scene; Rio de Janeiro is the geographic region with greater production; There has been growth in the number of works since the 2007 and increased collaboration.

Conclusions: the interest in Archival Science literature is increasing significantly; there was diversification of the publishing channels, mainly works of events and articles since 2013; the Archival Science is consolidating in Brazil with an increasing production, collaboration and interest in its scientific literature.
\end{abstract}

Keywords: Review of the literature. Scientific communication. Archival science. Brazil. Bibliometrics.

\section{Titulo}

Analisis de la produción científica de archivología en Brasil: una revisión de la literatura

Resumen

Introducción: Se presenta el resultado del levantamiento bibliográfico sobre la literatura científica de Archivología brasilera.

Objetivo: Identificar los aspectos de la literatura científica en Archivología, atreves de la investigación bibliográfica que busca presentar características de la configuración de la Archivología en Brasil.

Metodología: Se utilizó como fuentes bibliográficas: bases de datos, portales y servidores de referencia brasileiros donde se identificó 523 referencias de los cuales 15 textos fueron seleccionados e analizados en relación a: autoría, afiliación, año, tipo de publicación, tipo y tamaño de fuentes usadas, método, ámbito geográfico, resultados, entre otros aspectos.

Resultados: Los artículos científicos fueron las principales fuentes de estudio; el libro fue el canal más citado; el periódico Arquivo \& Administração y el Encontro Nacional de Pesquisa em Ciência da Informação fueron los más importantes en el escenario nacional; Rio de 
Janeiro es la región geográfica con mayor producción; se observó un crecimiento en el número de trabajos a partir del año 2007 al igual que el número de colaboración.

Conclusiones: El interés por la literatura en archivología está en aumento de forma significativa; Existe una diversificación de canales de publicación principalmente trabajos presentados en eventos y artículos publicados a partir del 2013; la Archivología se está consolidando en Brasil con el aumento de las publicaciones, colaboración e interés por su consolidación en la literatura científica.

Palabras-claves: Revisión de literatura. Comunicación científica. Archivística. Brasil. Bibliometria.

Recebido em: 10.04.2016

Aceito em: 18.11.2016 